\title{
Е.В. Грязнова
}

\section{ИНФОРМАЦИОННАЯ КУЛЬТУРОЛОГИЯ КАК НАУЧНОЕ НАПРАВЛЕНИЕ: ФИЛОСОФСКО-МЕТОДОЛОГИЧЕСКИЙ АНАЛИЗ}

Аннотация. Предметом исследования данной статьи является книга К.К. Колина и А.Д. Урсула «Информация и культура. Введение в информационную культурологию». Автор особое внимание уделяет анализу актуальных сегодня вопросов изложенных в книге, связанных с проблемами информатизации и перехода к глобальному информационному обществу, формированием нового для этого общества феномена «информационная культура». В качестве рекомендаций в статье предлагается построение типологии информационной культуры, разбираются примеры применения данной типологии для дальнейшего развития научного направления "информационная культурология". В качестве основных методов исследования используется анализ, обобщение, типологизация, сравнение, принцип системности, деятельностный и "сферный" подходы при изучении информационной культуры как социального феномена. Основными выводами проведенного исследования являются: 1) Рецензируемый материал достаточно широко и ёмко раскрывает основные аспекты научного направления "Информационная культурология" по пяти направлениям: предметология, терминология, методология, номология и праксиология. 2) В качестве рекомендаций можно отметить следующее: - более чётко типологизировать феномен "информационная культура"; - использовать понятие "виртуальная реальность", опираясь на информационную концепцию, что позволит избежать отождествлений его с понятием "социальная реальность"; - праксиология научного направления требует несколько большего достоверного и современного фактографического и статистического материала по излагаемым проблемам. 3) В целом представленное научное направление обеспечено научными публикациями, научными школами и научным потенциалом для дальнейшего развития.

Ключевые слова: информационная культурология, информационная культура, информационная деятельность, информационный потенциал, информационная культура управления, информационная культура образования, информационная культура медицины, информационная культура экономики, информационная культура экологии.

Abstract. The subject of this research is the book by K. K. Kolin and A. D. Ursul "Information and Culture. Introduction into the information Culturology". The author gives special attention to the analysis of the relevant questions expressed in this book, which are associated with the problems of informatization and transition towards the global information society, as well as formation of the new to such society phenomenon of "information culture". The article suggests structuring of the typology of information culture and examines the examples of implementation of this typology for further development of the "information culturology" as a scientific direction. The main conclusions consist in the following:1. The peer reviewed material fully reveals the main aspects of the scientific discipline "Information culturology" in five directions: subjectology, terminology, methodology, nomology, and praxeology.2. As a recommendation, we should note the following: - The phenomenon "information culture" should be more specifically typologized; - The notion "virtual reality" should be used based on the information concept; it will help to avoid its identification with the notion "social reality"'; - Praxeology of the scientific discipline requires a more reliable and contemporary factual and statistical material on the presented issues.

Key words: Peer review, Information culturology, Information culture, Information activity, Information potential, Information culture of administration, Information culture of education, Information culture of medicine, Information culture of economics, Information culture of ecology.

Рец. на книгу: Колин К.К., Урсул А.Д. Информация и культура. Введение в информационную культурологию. М.: Стратегические приоритеты, 2015. 300 с.
Эта книга интересна, прежде всего, тем, что в ней рассматриваются актуальные сегодня вопросы, связанные с проблемами информатизации и перехода к глобальному информационному обще- 
ству, формированием нового для этого общества феномена «информационная культура».

Казалось бы, работ подобной тематики сегодня выходит достаточно много. Однако следует отметить, что К.К. Колин и А.Д. Урсул предложили новую концепцию научного направления «Информационная культурология». В рамках предлагаемого ими подхода рассматриваются проблемы развития нового вида культуры, которая сегодня стремительно изменяет среду обитания человека, традиционные области его деятельности, стереотипы поведения и общения, духовные ценности и представления о качестве жизни, пространстве и времени.

Как известно, становление новых научных направлений и областей исследования начинается с определения предметной области - предметологии и категориального аппарата - терминологии. Они, в свою очередь, основываются на философском обосновании, формировании терминологии и определения границ своей предметной области. Авторы несколько лет назад осуществили первую монографическую публикацию на эту тему [1].

В рецензируемой книге К.К. Колин и А.Д.Урсул представили результаты данной работы и новый интересный материал по определению предметной области и разработке категориального аппарата научного направления «Информационная культурология». В частности, проведён глубокий анализ основных концептов научного направления: «информация», «культура», «информационная культура».

Мы, в свою очередь, можем подтвердить правильность и обоснованность результатов, полученных авторами материалом, отражённым и в наших публикациях [2; 3]. В наших работах в различных аспектах получили своё развитие идеи, предложенные авторами, что позволило разработать и новые концепции.

В качестве примера приведем разработанную нами концепцию информационной виртуальной реальности, в основе которой лежит атрибутивная концепция информации, созданная одним из авторов рецензируемой книги А.Д. Урсулом и определяемая как отражённое разнообразие. В рамках этой концепции информационное взаимодействие имеет место не только на уровне биотического и социального уровня Универсума, но и абиотического. Исходя из важнейшего сущностного свойства информации - способности проявлять себя только в процессе взаимодействия, можно сделать предположение, что вне взаимодействия информация (неотражённое разнообразие) также существует, но не актуально, а виртуально. Аналогично предлагается определить и способы существования двух других составляющих мироздания: возможность/ действительность (вещество) и потенциальность/ кинетичность (энергия). Употребление данных категорий в узком смысле не отменяет, а дополняет их общепринятое философское содержание. В результате определения виртуальности как способа существования разнообразия вне взаимодействия, т.е. в закодированном (пассивном) состоянии, появляется возможность введения дополнительных понятий: виртуация и информационный виртуал, смысл которых аналогичен понятийному ряду для энергетической составляющей: потенциальность, потенция, энергетический потенциал.

Виртуация и информация, как полярные способы существования разнообразия, образуют два вида реальности: виртуальную и информационную, единство которых может быть представлено в категории виртуально-информационная реальность - взаимосвязь существования разнообразия в активном и пассивном состояниях.

Концепция виртуально-информационной реальности позволяет расширить понятие Универсума и определить его как совокупность потенциально-кинетической, возможно-действительной и виртуально-информационной реальностей, что приводит к пониманию его как единства пассивного и активного бытия, представленного спектром состояний своих составляющих. Анализ виртуально-информационной реальности на всех уровнях организации Универсума был проведён нами в ряде работ и позволил обосновать универсальность вводимого понятия и внести определённый вклад в построение информационной картины мира, адекватной уровню создаваемой Человеком информационной Среды Универсума.

Возможность разработки новых концепций на базе концепции информации, изложенной в рецензируемой книге, свидетельствует о многолетнем научном сотрудничестве и преемственности в рамках нового научного направления «Информационная культурология».

Далее авторы книги предлагают научный анализ таких категорий как «эволюционная информодинамика», «информационная глобалистика», «ноосферная культура», «электронная культура», «виртуализация общества», «информационная этика» и др. Мы можем в целом согласиться с предлагаемыми авторами подходами к определению понятий. Однако следует обратить внимание на некоторые нюансы. Например, раскрывая понятие «виртуализация общества» следует исходить из понимания того, что общество относится к социальному уровню Универсума, субстратом которого является человек и как родовое понятие он начинается там, где социальное переходит границы 
естественного, приобретая статус искусственного. В многочисленных работах и в рецензируемой книге, в том числе, термины «виртуальное» и «социальное» употребляются чаще всего как синонимы. Правомерно ли такое отождествление?

Сегодня достаточно распространённым становится направление в понимании виртуальной реальности, когда признаётся, что виртуализация социального пространства происходит не только с помощью компьютерных систем, но и иными способами. Авторы рецензируемой книги в своих исследованиях, опираются в основном на подобные работы, например, Д.В. Иванова. В частности, обобщая опыт зарубежных авторов, Д.В. Иванов пишет: «Виртуализация в таком случае это любое замещение реальности её симуляцией, образом - не обязательно с помощью компьютерной техники, но обязательно с применением логики виртуальной реальности...» [22, с. 18]. Таким образом, по мнению Д.В. Иванова, виртуальная реальность создаётся на базе социальной реальности именно там, где субъект взаимодействует с формами без прототипов. Интересными представляются перечисленные автором и «универсальные свойства виртуальной реальности»: «...нематериальность воздействия (изображаемое производит эффекты, характерные для вещественного); условность параметров (объекты искусственны и изменяемы); эфемерность (свобода входа/выхода обеспечивает возможность прерывания и возобновления существования» [22, c.18]. Данные свойства характерны для знаков, симулякров, фантазий и, соответственно, проявляются в том пространстве, которое создают. Но вряд ли можно обнаружить эти свойства у виртуальных частиц, что не позволяет считать их как универсальные для всех виртуальных объектов.

В более поздних работах отечественных исследователей встречаются концепции, в которых вся социальная реальность признаётся виртуальной. Так, например, по мнению В.М. Быченкова, анонимность и безличность социальной реальности, особенно в современном «абстрактном» и «кибернетическом» обществе, дополняет ещё одно её определение - виртуальность (фантомность, фиктивность), охватывающее как предметные, так и субъектные её элементы. По мнению В.М. Быченкова, социальная реальность виртуальна по способу своего существования, т.к. она существует в надындивидуальной реальности. Таким образом, виртуальными признаются социальные институты: совокупность знаков для выражения мыслей, кредитно-денежная система, профессиональные обычаи, социальные нормы и т.д., а также социальные институты-образования: всевозможные пред- приятия, учреждения, заведения и т.д. [23, с. 78]. Получается, что вся сфера общественных отношений есть виртуальная реальность. В социальной реальности не остаётся ничего социального - всё виртуально, а виртуально, потому что символично [24, с. 351-352]. На наш взгляд, авторы правы в том, что используют понятие виртуальности для обозначения реальности «надындивидуальной». Однако без специального сравнительного анализа самих понятий «социальное» и «виртуальное» они оказываются тождественными.

Обобщая работы данного направления, мы приходим к выводу, что происходит явное отождествление виртуальной и социальной реальности. Если в гуманитарном направлении виртуалистики понятие «виртуальная реальность» теряется на фоне понятий психологическая, субъективная, идеальная реальность, то здесь оно растворяется в понятии «социальная реальность», не приобретая при этом самостоятельного смысла. Учитывая, что понятие социальной реальности можно и нужно рассматривать в плане информационных процессов, как основных и наиболее значимых в обществе, то и понятие виртуальной реальности также должно анализироваться в информационном аспекте. Иными словами, родовые признаки социальной виртуальности следует искать не в социальности самой по себе, а в информационной её составляющей.

Подобное отождествление понятий происходит, вероятно, потому, что авторы, разрабатывая понятие социальной виртуальной реальности, опираются на понятие социальной информации, не обозначая этот факт в явном виде. Действительно, знак есть минимальный носитель языковой информации. Следует признать, что символическая и знаковая составляющие сознания оказываются видом информации, которую принято называть социальной, тогда как последняя и определяет содержание социальной реальности. Социальная реальность вне социального взаимодействия существует как виртуальная реальность, например, культура как социальный код, общественные отношения, социальные институты и др. Только в процессе актуализации общественных отношений через деятельность и общение, сознание в информационном взаимодействии девиртуализирует социальный код, превращая его в информацию. Подобное применение категории социальной виртуально-информационной реальности может в некоторой степени соотнести веберовское понимание социальных структур как категорий определённых видов совместной деятельности людей и дюркгеймовское признание автономности социальной реальности, существующей вне человека. 
Именно как виртуально-информационная составляющая социальной реальности может быть представлена и символическая реальность.

Особенностями виртуально-информационной реальности социального уровня оказываются: появление принципиально нового вида информации социальной и её виртуализации - культурного кода; возникновение виртуальных отношений - общественных, которые, актуализируясь, превращаются в различные виды социального взаимодействия, основой которых является информационный процесс.

Применение информационного подхода к понятию виртуальной реальности в наших многочисленных работах $[2 ; 3 ; 6 ; 7 ; 25]$ позволило показать, что содержательная близость понятий «идеальное», «психическое», «социальное», «техническое» и даже «физическое» объясняется наличием в каждом из этих феноменов родового признака - виртуально-информационного состояния.

Возвращаясь к материалам рецензируемой книги, отметим, что изучению предметного поля информационной культурологии посвящён специальный раздел. Авторы предлагают выделить ряд основных направлений развития предмета информационной культурологии:

1. Философские основы информационной культурологии;

2. Информационная культура личности;

3. Информационная культура корпоративных, государственных и социальных структур;

4. Электронная культура;

5. Социально-культурологические проблемы развития сетевых структур общества и информационных коммуникаций;

6. Информационные технологии в искусстве и творчестве;

7. Культурологические аспекты информационной безопасности;

8. Информационная этика;

9. Информационная культура международного общения.

Данные направления охватывают основную часть предметного поля информационной культурологии. Однако следует отметить некую неупорядоченность в систематизации. В данном перечне не прослеживаются чёткие критерии выделения направлений и оснований типологизации. Мы можем предложить со своей стороны следующий подход к определению границ предметного поля информационной культурологии.

Так как информационная культурология охватывает практически все сферы общественной жизни, что обосновывается авторами в рецензируемой книге, то делить предмет на направления можно по данному основанию. Достаточно полная типология сфер общественной жизни разработана д.ф.н., профессором Л.А. Зеленовым [4; 5].

Основываясь на разработанной им типологии, получим 8 аспектов информационной культуры:

1. Информационная культура экономической сферы;

2. Информационная культура экологической сферы;

3. Информационная культура управленческой сферы;

4. Информационная культура педагогической сферы;

5. Информационная культура научной сферы;

6. Информационная культура художественной сферы;

7. Информационная культура физкультурной сферы;

8. Информационная культура медицинской сферы.

Далее, учитывая формы социального субъекта, можно выделять и такие аспекты как:

1. Информационная культура личности;

2. Информационная культура группы людей.

Можно добавить и другие формы субъекта: нация, страна и т.д.

Если теперь учесть структуру сферы общественной жизни (потенциал, деятельность, социальные институты и отношения) [4; 5], то получим следующий ряд аспектов информационной культуры:

1. Информационный потенциал культуры (потребности и способности в зависимости от вида сферы: экономические, экологические и т.д.). Например, информационный потенциал экономической деятельности;

2. Информационная деятельность (экономическая, экологическая и т.д., 8 видов);

3. Информационная культура социальных отношений (8 видов);

4. Информационная культура социальных институтов (8 видов).

Сведём полученные результаты в одну таблицу (см. табл. 1).

Теперь аспекты информационной культуры упорядочены. Например, информационная культура личности может анализироваться по видам деятельности, скажем экономическая деятельность - ячейка № 2. В этом случае речь идёт о формировании и реализации информационной культуры личности в экономической деятельности в условиях информатизации общества. Если рассматривается коллективный субъект, например, общество, то этот тип информационной культуры ячейка № 6 и речь пойдёт об информационной 


\section{Философия и культура 3(99) • 2016}

Таблица 1.

\begin{tabular}{|c|c|c|c|c|c|}
\hline \multirow{2}{*}{$\begin{array}{c}\text { Сфера } \\
\text { общественной жизни }\end{array}$} & \multirow{2}{*}{$\begin{array}{c}\text { Вид } \\
\text { субъекта }\end{array}$} & \multicolumn{4}{|c|}{ Элементы сферы общественной жизни } \\
\hline & & потенциал & деятельность & социальные отношения & социальные институты \\
\hline \multirow[t]{2}{*}{ экономическая } & ЛИчность & 1 & 2 & 3 & 4 \\
\hline & коллектив & 5 & 6 & 7 & 8 \\
\hline \multirow[t]{2}{*}{ экологическая } & личность & 9 & 10 & 11 & 12 \\
\hline & коллектив & 13 & 14 & 15 & 16 \\
\hline \multirow[t]{2}{*}{ научная } & личность & 17 & 18 & 19 & 20 \\
\hline & коллектив & 21 & 22 & 23 & 24 \\
\hline \multirow[t]{2}{*}{ художественная } & личность & 25 & 26 & 27 & 28 \\
\hline & коллектив & 29 & 30 & 31 & 32 \\
\hline \multirow[t]{2}{*}{ медицинская } & личность & 33 & 34 & 35 & 36 \\
\hline & коллектив & 37 & 38 & 39 & 40 \\
\hline \multirow[t]{2}{*}{ физкультурная } & личность & 41 & 42 & 43 & 44 \\
\hline & коллектив & 45 & 46 & 47 & 48 \\
\hline \multirow[t]{2}{*}{ управленческая } & личность & 49 & 50 & 51 & 52 \\
\hline & коллектив & 53 & 54 & 55 & 56 \\
\hline \multirow[t]{2}{*}{ педагогическая } & личность & 57 & 58 & 59 & 60 \\
\hline & коллектив & 61 & 62 & 63 & 64 \\
\hline
\end{tabular}

культуре современного информационного общества в экономической деятельности. Исследование информационной культуры по всей строке (ячейки № 1-8) позволит выйти на диалектический анализ информационной культуры в экономической сфере общества в целом.

Основные аспекты информационной культуры, представленные в рецензируемой книге, замечательно вписываются в данную типологию. Так, авторы, дав определение информационной культуры, пишут: «Согласно этому определению, основными компонентами информационной культуры являются:

1. Информационные качества человека, формируемые у него в течение жизни и профессиональной деятельности. К ним относятся информационная культура личности, информационная и компьютерная компетентность и грамотность, информационное миропонимание и информационное мировоззрение» - стр. 106. Собственно видно, что речь идёт об информационных потребностях и способностях человека (информационном потенциале), необходимом для реализации того или иного вида деятельности. В предлагаемой нами типологии данные аспекты займут ячейки столбца «потенциал» с конкретизаций по виду деятельности и субъекта.

Далее авторы определяют в качестве элементов информационной культуры: «Многообразие предметов новой информационной культуры - материальных, духовных и художественных. Это могут быть электронные книги, электронные библиотеки, музеи и картинные галереи, произведения экранной культуры и т.п. ... Способы деятельности человека в информационной сфере. К ним относятся информационные технологии, которые создаются и используются в сфере культуры, как специ- алистами, так и обычными пользователями (поиск информации, мультимедиа, виртуальная реальность и др.)» - стр. 106. Данные элементы являются объектом, средством, средой информационной деятельности и могут рассматриваться в столбце «деятельность».

Так же найдут своё место и выделяемые авторами направления исследования информационной культуры корпоративных, государственных и социальных структур, попадающие в столбцы «социальные отношения» и «социальные институты» по различным типам деятельности.

Можно определить место в типологии практически всем аспектам информационной культуры, о которых пишут авторы. Например, раздел «Информационная культура и образование» (стр. 148-154) охватывает вопросы информационной культуры педагогической сферы общества (ячейки 57-64); раздел «Электронное правительство» (стр. 123$125)$ - вопросы информационной культуры в сфере управленческой деятельности (ячейки 49-56); раздел «Здравоохранение и социальная защита населения» (стр. 126-127) - вопросы информационной культуры в медицинской сфере (ячейки 33-40); раздел «Виртуализация экономики» (стр. 236-240) - вопросы информационной культуры в экономической сфере общества (ячейки 1-8); раздел «Становление ноосферной культуры» (стр. 85-93) - вопросы информационной культуры в экологической сфере общества (ячейки 9-16) и т.д.

Книга К.К. Колина и А.Д.Урсула отличается тем, что в ней представлен широкий спектр вопросов и проблем, охватывающие не только информационный аспект земной цивилизации, но и внецивилизационное измерение. Например, в разделе «Цивилизация и культура в глобально-космическом измерении» (стр. 77-83) поднимаются про- 
блема информационной экспансии человечества и внеземных цивилизаций.

Неотъемлемым основанием любого научного направления является методология - система методов исследования. В рецензируемой книге представлена солидная методологическая база, разрабатываемая и апробируемая авторами на протяжении многих лет работы. В первую очередь речь идёт об информационном подходе, в развитии которого авторы принимают активнейшее участие на страницах публикаций. Практически все разделы книги используют категории и понятия информационного подхода. Для научных работников эта книга может служить пособием по применению информационного подхода в изучении информационного аспекта эволюционного развития, разработки концепций информационной культуры и цивилизации и т.п.

В исследованиях, представленных в книге, используются и такие методы как деятельностный подход. В частности, интересным представляется выход на информационную концепцию деятельности. Следует отметить и развитие авторами методологических оснований синергетики, ноосферизма, глобалистики и др. в рамках информационного подхода.

Одной из важнейших составляющих любого научного направления является наличие законов и принципов. В рецензируемой книге анализируются основные законы, закономерности и принципы развития и существования информационной культуры. Этим вопросам посвящены, например, разделы «Эволюционная информодинамика», «Информационное видение культурной эволюции», «Становление ноосферной культуры», «Культурологические аспекты развития информационной цивилизации», «Философские проблемы информационной культурологии» и др.

Последний обязательный элемент научного направления - праксиология, т.е. практическое применение. В книге этот вопрос представлен объёмным материалом, который можно озаглавить
«Проблемы прикладной информационной культурологии». Это, прежде всего, вопросы, рассматриваемые в разделах «Человек в информационном обществе», «Информационное неравенство как глобальная проблема», «Проблема многоязычия в информационном обществе», «Виртуализация общества как глобальная угроза» и др.

Здесь следует отметить некоторый недостаток именно практического материала в книге. Как мы отметили, этот раздел содержит объёмный, но теоретический материал. С одной стороны, авторы и не ставили перед собой подобной задачи. Но, с другой стороны, когда речь идёт о научном направлении, вопросы практического или прикладного характера обязательно должны разрабатываться. Например, говоря о проблемах человека в информационном обществе, можно опираться на различные практические результаты в исследованиях психологов, педагогов, социологов. Скажем, когда излагается материал о возможных социальных последствиях виртуализации науки и образования, было бы интересно подкрепить теоретические предположения, например, фактами распространения киберзависимости, различного рода психических заболеваний, социальной дезадаптации и т.п., которые сегодня фиксируются в научных исследованиях. Тоже самое, можно сказать и о проблемах информатизации и формирования информационной культуры в сферах здравоохранения, управления, экономики и т.д., анализ которых даётся в современных научных публикациях с опорой на конкретные факты и цифры.

Наши исследования созвучны с проблемами, поднимаемыми авторами книги и могут послужить научным вкладом в развитие научного направления «Информационная культурология» $[6 ; 7 ; 8]$.

В заключении хочется выразить глубокую благодарность авторам за их научное творчество, за методологическую помощь, которую они оказывают молодому поколению учёных.

\section{Список литературы:}

1. Колин К.К., Урсул А.Д. Информационная культурология. Предмет и задачи нового научного направления. Саарбрюккен (Германия): Lambert academic publishing, 2011. 249 с.

2. Грязнова Е.В. Виртуально-информационная реальность в системе «Человек - Универсум». Н. Новгород: ННГУ, 2006.255 с.

3. Грязнова Е.В., Урсул А.Д. Информация и виртуальная реальность: концептуальные основания проблемы. Н. Новгород: ННГАСУ, 2012. 159 с.

4. Зеленов Л.А. Методология исследования социума // Вестник Нижегородского университета им. Н.И. Лобачевского. 2012. Вып. № 1-3. С. 101-111.

5. Зеленов Л.А. Социальные константы. Н. Новгород: Новация, 2010. 174 с.

6. Грязнова Е.В. Информационная реальность и социум. Н. Новгород: ННГАСУ, 2010. 203 с.

7. Грязнова Е.В., Пасхин Е.Н., Шиловская Е.Е. Человек в информационном мире. М.: Пушкинский институт, 2010.180 с.

8. Грязнова Е.В. Информационная социализация личности // Социология власти. 2010. № 1. С. 18-25.

9. Колин К.К. Виртуализация общества - новая угроза для его стабильности // Синергетическая парадигма. Человек и общество в условиях нестабильности: сб. науч. тр. М.: РАГС, 2003. С. 449-462. 
10. Колин К.К. Информационный подход как фундаментальный метод научного познания // Межотраслевая информационная служба. 1998. № 1. С. 3-17.

11. Колин К.К. Информационное пространство культуры: проблема многоязычия в информационном обществе // Вестник КемГУКИ. 2011. № 15. С. 8-17.

12. Колин К.К. Информационная цивилизация. М.: Институт проблем информатики РАН, 2001. 112 с.

13. Урсул А.Д. Информация и культура // Философия и культура. 2011. № 2. С. 98-112.

14. Урсул А.Д. Исследование информационных и глобальных процессов: междисциплинарные подходы и связи // NB: Проблемы общества и политики. 2012. № 3. С. 154-201.

15. Урсул А.Д. Культура как информационный феномен // NB: Философские исследования. 2013. № 8. С. 295 -355.

16. Урсул А.Д. Феномен ноосферы: Глобальная эволюция и ноосферогенез. М.: Ленанд, 2015. 155 с.

17. Грязнова Е.В. Идентификация человека в информационной реальности // Психология и психотехника. 2013 . № 4 . C. 371-379. DOI: 10.7256/2070-8955.2013.04.8.

18. Рыжов Р.С. Правовое регулирование отношений, связанных с информационными технологиями защитой информации // Административное и муниципальное право. 2011. № 9. С. 64-68.

19. Грязнова Е.В. Информационная культура медицинских учреждений: проблемы и перспективы // Человек и культура. 2015. № 1. C. 92-111. DOI: 10.7256/2409-8744.2015.1.14850. URL: http://www.e-notabene.ru/ca/article_14850.html.

20. Грязнова Е.В., Матяева И.Л. Деятельностный подход в исследовании дистанционного образования // Психология и психотехника. 2014. № 3. С. 304-311. DOI: 10.7256/2070-8955.2014.3.11095.

21. Шульц В.Л., Кульба В.В., Шелков А.Б., Чернов И.В. Информационное управление в условиях глобализации и геополитического противоборства // NB: Национальная безопасность. 2015. № 2. C. 202-243. DOI: 10.7256/20738560.2015.2.14622.

22. Иванов Д.В. Виртуализация общества. СПб., 2000. 206 с.

23. Быченков В.М. Без имени, без облика, без тела // Общество и книга: от Гуттенберга до Интернета. М., 2001. С. $61-85$.

24. Кастельс М. Информационная эпоха: экономика, общество и культура. М., 2000. 550 с.

25. Грязнова Е.В. Виртуально-информационная реальность в системе «Человек - Универсум». Н. Новгород: ННГУ, 2006.255 с.

References (transliterated):

1. Kolin K.K., Ursul A.D. Informatsionnaya kul'turologiya. Predmet i zadachi novogo nauchnogo napravleniya. Saarbryukken (Germaniya): Lambert academic publishing, 2011.249 s.

2. Gryaznova E.V. Virtual'no-informatsionnaya real'nost' v sisteme «Chelovek - Universum». N. Novgorod: NNGU, 2006.255 s.

3. Gryaznova E.V., Ursul A.D. Informatsiya i virtual'naya real'nost': kontseptual'nye osnovaniya problemy. N. Novgorod: NNGASU, 2012. $159 \mathrm{~s}$.

4. Zelenov L.A. Metodologiya issledovaniya sotsiuma // Vestnik Nizhegorodskogo universiteta im. N.I. Lobachevskogo. 2012. Vyp. № 1-3. S. 101-111.

5. Zelenov L.A. Sotsial'nye konstanty. N. Novgorod: Novatsiya, 2010.174 s.

6. Gryaznova E.V. Informatsionnaya real'nost' i sotsium. N. Novgorod: NNGASU, 2010. 203 s.

7. Gryaznova E.V., Paskhin E.N., Shilovskaya E.E. Chelovek v informatsionnom mire. M.: Pushkinskii institut, 2010.180 s.

8. Gryaznova E.V. Informatsionnaya sotsializatsiya lichnosti // Sotsiologiya vlasti. 2010. № 1. S. 18-25.

9. Kolin K.K. Virtualizatsiya obshchestva - novaya ugroza dlya ego stabil'nosti // Sinergeticheskaya paradigma. Chelovek i obshchestvo v usloviyakh nestabil'nosti: sb. nauch. tr. M.: RAGS, 2003. S. 449-462.

10. Kolin K.K. Informatsionnyi podkhod kak fundamental'nyi metod nauchnogo poznaniya // Mezhotraslevaya informatsionnaya sluzhba. 1998. № 1. S. 3-17.

11. Kolin K.K. Informatsionnoe prostranstvo kul'tury: problema mnogoyazychiya v informatsionnom obshchestve // Vestnik KemGUKI. 2011. № 15. S. 8-17.

12. Kolin K.K. Informatsionnaya tsivilizatsiya. M.: Institut problem informatiki RAN, 2001. $112 \mathrm{~s}$.

13. Ursul A.D. Informatsiya i kul'tura // Filosofiya i kul'tura. 2011. № 2. S. 98-112.

14. Ursul A.D. Issledovanie informatsionnykh i global'nykh protsessov: mezhdistsiplinarnye podkhody i svyazi // NB: Problemy obshchestva i politiki. 2012. № 3. S. 154-201.

15. Ursul A.D. Kul'tura kak informatsionnyi fenomen // NB: Filosofskie issledovaniya. 2013. № 8. S. 295-355.

16. Ursul A.D. Fenomen noosfery: Global'naya evolyutsiya i noosferogenez. M.: Lenand, 2015. 155 s.

17. Gryaznova E.V. Identifikatsiya cheloveka v informatsionnoi real'nosti // Psikhologiya i psikhotekhnika. 2013. № 4. S. 371379. DOI: 10.7256/2070-8955.2013.04.8.

18. Ryzhov R.S. Pravovoe regulirovanie otnoshenii, svyazannykh s informatsionnymi tekhnologiyami zashchitoi informatsii // Administrativnoe i munitsipal'noe pravo. 2011. № 9. S. 64-68.

19. Gryaznova E.V. Informatsionnaya kul'tura meditsinskikh uchrezhdenii: problemy i perspektivy // Chelovek i kul'tura. 2015. № 1. S. 92-111. DOI: 10.7256/2409-8744.2015.1.14850. URL: http://www.e-notabene.ru/ca/article_14850.html.

20. Gryaznova E.V., Matyaeva I.L. Deyatel'nostnyi podkhod v issledovanii distantsionnogo obrazovaniya // Psikhologiya i psikhotekhnika. 2014. № 3. S. 304-311. DOI: 10.7256/2070-8955.2014.3.11095.

21. Shul'ts V.L., Kul'ba V.V., Shelkov A.B., Chernov I.V. Informatsionnoe upravlenie v usloviyakh globalizatsii i geopoliticheskogo protivoborstva // NB: Natsional'naya bezopasnost'. 2015. № 2. S. 202-243. DOI: 10.7256/2073-8560.2015.2.14622.

22. Ivanov D.V. Virtualizatsiya obshchestva. SPb., 2000. $206 \mathrm{s.}$

23. Bychenkov V.M. Bez imeni, bez oblika, bez tela // Obshchestvo i kniga: ot Guttenberga do Interneta. M., 2001. S. 61-85.

24. Kastel's M. Informatsionnaya epokha: ekonomika, obshchestvo i kul'tura. M., 2000. $550 \mathrm{s.}$

25. Gryaznova E.V. Virtual'no-informatsionnaya real'nost' v sisteme «Chelovek - Universum». N. Novgorod: NNGU, 2006.255 s. 